\title{
Functional disability and associated factors among patients with severe mental illness attending psychiatry outpatient unit at Ayder comprehensive specialized hospital, Mekelle, Ethiopia: a cross- sectional study.
}

Tesfalem Amare ( $\nabla$ tesfaye.araya@yahoo.com )

Mekelle University College of Health Sciences

Natnael Seifu

Mekelle University

Mirkat Shewangzaw

Mekelle University

Primary research

Keywords: functional disability, severe mental illness, Mekelle, Ethiopia

Posted Date: April 9th, 2020

DOI: https://doi.org/10.21203/rs.3.rs-18550/v2

License: (1) (i) This work is licensed under a Creative Commons Attribution 4.0 International License.

Read Full License 
The authors have withdrawn this preprint from Research Square 